\title{
PERFORMANCE EVALUATION OF CEMENT MORTAR BLENDED NANOFIBRILLATED CELLULOSE
}

\author{
Priya Patel \\ Civil and Environmental Engineering Department, V.J.T.I, Mumbai, India \\ Dr. A. S. Wayal \\ Associate Professor, \\ Civil \& Environmental Engineering Department, V.J.T.I, Mumbai, India \\ Dr. A. K. Bharimalla \\ Senior Scientist, \\ ICAR- Central Institute for Research on Cotton Technology, Mumbai, India
}

\begin{abstract}
This paper focuses on the effect on rendering cement mortar by addition of aqueous Nanofibrillated Cellulose. For preparation of the mortar mix crushed sand was used. The Nanofibrillated Cellulose made from cotton linter were added in the percentage of $0.32 \%, 0.64 \%, 0.96 \%, 1.28 \%$ and $1.60 \%$ by weight of cement was added in cement mortar in order to observe its effect on fresh and hardened properties of the cement mortar. The results showed by addition of Nanofibrillated Cellulose lead to decrease in the fresh density and bleeding rate of cement mortar. The results also showed that by addition of Nanofibrillated Cellulose in the cement mortar leads to increase in the rate of capillary and moisture absorption in the mortar and decrease in the length of the cracks formed on the plastered surface.
\end{abstract}

Keyword head: Nanofibrillated Cellulose (NFC), Cement Mortar, Cotton Linter.

Cite this Article: Priya Patel, Dr. A. S. Wayal and Dr. A. K. Bharimalla, Performance Evaluation of Cement Mortar Blended Nano fibrillated Cellulose, International Journal of Civil Engineering and Technology, 11(03), 2020, pp.169-176

https://iaeme.com/Home/issue/IJCIET?Volume=11\&Issue=3

\section{INTRODUCTION}

Cellulose is the product of biosynthesis from plants, animals, or bacteria, while the general term 'nanocellulose' refers to cellulosic extracts or processed materials, having defined nanoscale structural dimensions [9]. Nanocellulose is nano-structured cellulose which may either 
be Nanofibrillated Cellulose (NFC) also called Cellulose Nanofibrils (CNF) or Nanocrystalline Cellulose (NCC) [6]. It has been in development for about 40 years, getting its start in New Jersey at ITT Rayonier Labs in 1977 [5].

Nanofibrillated cellulose can be obtained from natural fibres by subjecting them to mechanical, chemical or enzymatic treatments [2]. The NFC obtained from chemical treatment results into high chemical usage and by products, NFC obtained from enzymatic or bacterial treatment results in a very slow process whereas, NFC obtained by mechanical results in a fast process giving no effluent. The disintegration of cellulose fibres can lead to high crystalline nanofibers with a Young's modulus of about $138 \mathrm{GPa}$ and tensile strength of $7.5 \mathrm{GPa}$ [1]. NFC has several unique characteristics, such as their unique morphology, low density, very large surface to volume ratio, high surface area, good mechanical properties including a high Young's modulus, high tensile strength and low coefficient of thermal expansion (CTE) [8].

Nanofibrillated Cellulose is giving good mechanical property as well as environment friendly light weight has been the main driver for their use as alternative for harmful asbestos in cement mortar composites. It also enhances ductility, flexibility and crack resistance. Apart from these due to its cost effectiveness, NFC is a very interesting option for building industry mainly in less developed countries and countries that need low cost construction [2].

Nano material is bringing revolution in many industries. The cracking and load induced deformations of cement composites originate at the nanoscale [7]. Thus, in order to enhance the mechanical strength of cement-based materials, nano-sized cellulose fibres with very high specific surface area as reinforcement can be used to restrict the nanosized cracks developed in the cement mortar.

The aim of this work is to evaluate the capacity of Nanofibrillated Cellulose as a potential reinforcement to produce high performance cement mortar. For this purpose, mortar reinforced with Nanofibrillated Cellulose was compared with the controlled sample.

\section{MATERIALS AND SPECIMEN PREPARATION}

\subsection{Materials}

Bharti OPC grade 53 cement was used in this research. Crushed sand passing $2.36 \mathrm{~mm}$ sieve manufactured by Lafarge Aggregates \& Concrete India Pvt. Ltd was used in this research. Chryso ${ }^{\circledR}$ Tard SRC 80 , retarder was used at a maximum dosage of $0.06 \%$ by weight of cement was used in order to obtain workable mortar. Nanofibrillated cellulose (NFC) in aqueous form manufactured by ICAR- Central Institute for Research on Cotton Technology, Mumbai with solid content of $1.59 \%$ was used in this research.

\subsection{Specimen Preparation}

Cement and crushed sand in the proportion of 1:4 (by volume) was used in the research. Six trial mix with NFC content of $0.32 \%, 0.64 \%, 0.96 \%, 1.28 \%$ and $1.60 \%$ by weight of cement (i.e. $20.0 \%, 40.0 \%, 60.0 \%, 80.0 \%$ and $100.0 \%$ NFC aqueous solution by weight of cement). Water/cement ratio of 1.03 was used keeping constant for all trial mix. Retarder was added with a dosage of $0.06 \%$ by weight of cement in order to obtain desired workability. Nanofibrillated Cellulose solution was stirred thoroughly before using it in the mix, all the ingredients were weighed properly and mortar was made. 


\subsection{Fibre Treatment}

Nanofibrillated cellulose used was prepared by homogenization from Microfibrillated Cellulose (MFC) which was prepared by cotton linter. The MFC was prepared from cotton linters by traditional hydrochloric acid hydrolysis process and treated with zinc chloride for 2 hours for swelling. After swelling, the MFC was completely rinsed in water and subjected to homogenization process up to 40.000 psi pressure. The size of NFC was analysed by Scanning Electron Microscope and the average lateral size of Nanofibrillated Cellulose observed after refining for $1 \mathrm{hr} ., 2 \mathrm{hrs}$. and $3 \mathrm{hrs}$. are $152 \mathrm{~nm} ., 150 \mathrm{~nm}$. and $114 \mathrm{~nm}$. respectively.

\section{TEST PROCEDURE}

For finding the properties of fresh mortar slump cone test was conducted for finding the workability of the mortar, Humboldt Air meter was used to find the air content. Fresh density was found by measuring the weight of the specimen filled in a 3-litre container. Rendering rebound loss was found by applying the mortar on brick wall and AAC Block wall substrate and the wastage which occurred is weighed divided by the total weight of mortar taken for plastering gives the rebound loss. For finding the bleeding rate the fresh mortar was weighed $2 \mathrm{~kg}$. in a fixed container and allowed to settle for $3 \mathrm{hrs}$. the amount of water bleeded at the top was removed by using pipette and weighed and bleeding rate was measured.

Hardened properties of mortar were found by conducting Compressive Strength test, Capillary Absorption test, Moisture Absorption test and length of the cracks formed on the plastered surface was measured. For Compressive Strength test, cubes of size $0.76 \mathrm{~mm} \times 0.76 \mathrm{~mm} \times 0.76 \mathrm{~mm}$ was casted and Load was applied using CTM and tested for $3,7,14,28$ days. For Capillary Absorption test, Prisms of size $40 \mathrm{~mm} \times 40 \mathrm{~mm} \times 160 \mathrm{~mm}$ were casted and kept in a humidity chamber with relative humidity of $(65 \pm 5) \%$ and temperature $(20 \pm 2)^{\circ} \mathrm{C}$. The prisms were then tested for $3,24,48,72 \mathrm{hrs}$ for the capillary rise by keeping them in a tray filled with $1.5 \mathrm{~cm}$ water. Moisture Absorption of the mortar was found at the surface and at $10 \mathrm{~mm}$ depth of the plastered surface by using ETI 7000 moisture meter. For this Moisture of mortar before and after curing by spraying water on the surface were found and the difference between the moisture gives the moisture absorption of the mortar. The length of the cracks was formed on the plastered surface was measured with the help of Vernier calliper.

\section{RESULTS AND DISCUSSION}

\subsection{Workability}

Slump height of each mortar mix taken at an interval of half an hour is as shown in Figure 1. It can be clearly seen that the workability of cement mortar decreases as the dosage of NFC increases in the mortar. The highest workability was observed for mix 1 i.e. Control mix.

\subsection{Fresh Density}

Figure 2 shows the values of Fresh density for each mix of cement mortar. Fresh density of the mortar decreases as the content of NFC solution in the mortar increases. Maximum density was observed for Control Mix. As the density decreased the yield of the mortar also decreased resulting in decrease in the weight of the cement mortar. 


\subsection{Air Content}

Values of the percentage of entrapped air in the cement mortar is as shown in Figure 3. It can be observed as the as the dosage of NFC solution increases the percentage of voids present in the mortar increases. The percentage of voids increases as the dosage increases due to decrease in the density of the mortar.

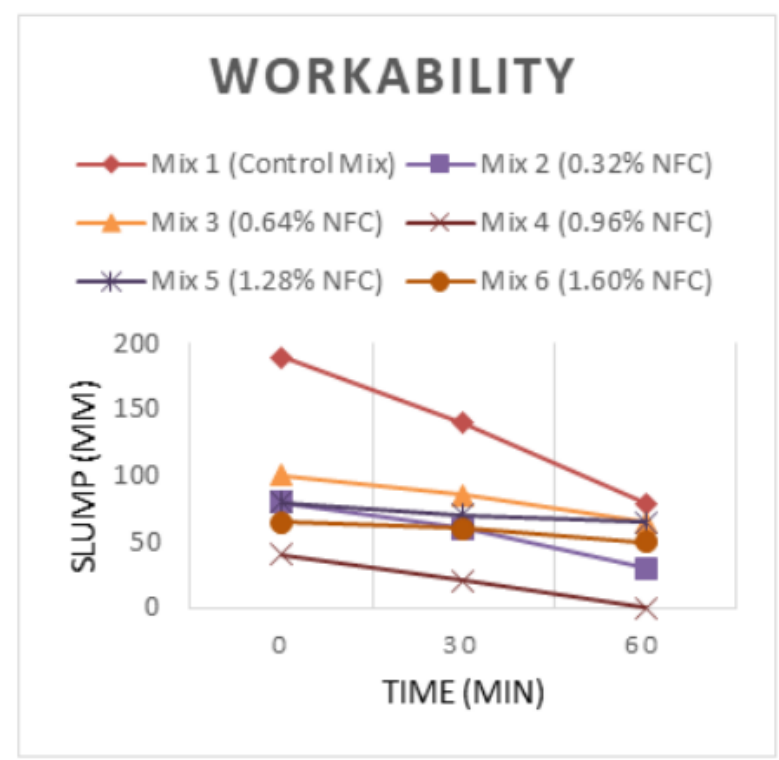

Figure 1 Workability Variation for all Mix

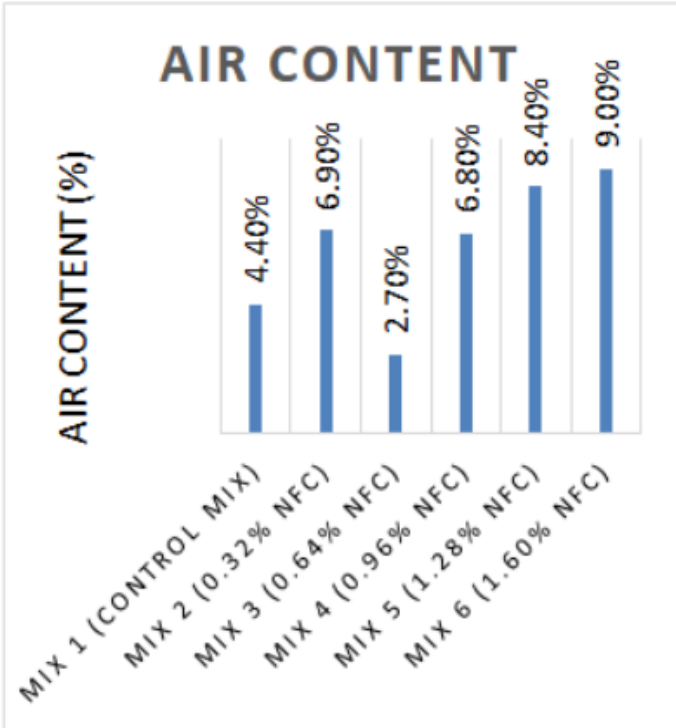

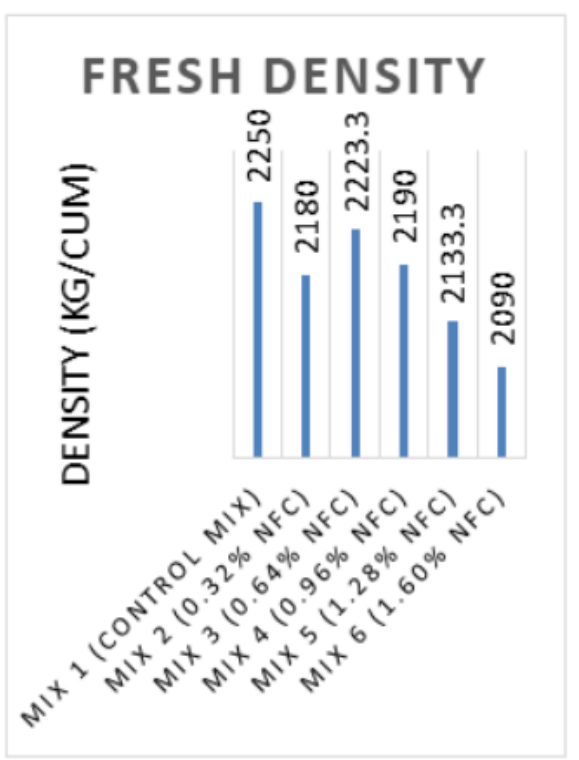

Figure 2 Fresh Density variation for all Mix

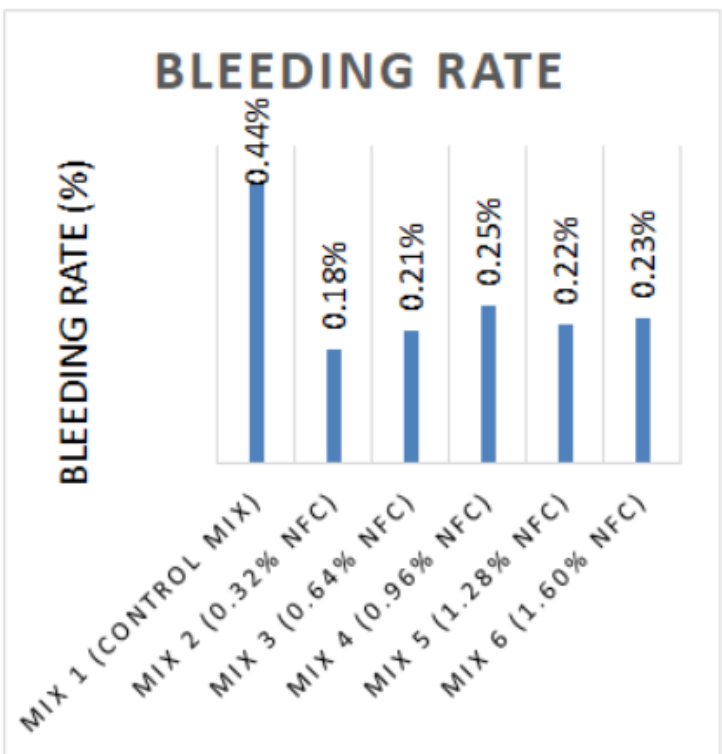

Figure 3 Variation in Air Content for all Mix Figure 4 Variation in bleeding rate for all Mix

\subsection{Bleeding Rate}

The amount of bleeding decreased when NFC Solution was added in the cement mortar as compared to the mix which did not contain NFC solution as indicated in Figure 4. This phenomenon occurred as the NFC absorbed the water from the mortar resulting in less bleeding. However, the amount of bleeding with different dosage of NFC Solution was 
observed to be more or less the same. Hence the amount of bleeding did not depend on the amount of NFC solution added in the mortar.

\subsection{Compressive Strength}

As the dosage of NFC solution in the mortar increases the compressive strength of the mortar cubes decreases indicated in Figure 5. Maximum compressive strength for 3,7,14 and 28 days was observed for the mix which did not contain NFC solution. Minimum compressive strength for 3, 7 and 14 days was observed for the mix which contained $0.96 \%$ of NFC (i.e. $60 \%$ of NFC solution) and minimum compressive strength for 28 days was observed for mix containing $1.60 \%$ NFC (i.e. $100 \%$ NFC solution).

\subsection{Capillary Rise}

Figure 6 shows the rate of capillary absorption up to $72 \mathrm{hrs}$. for each trial mix. The rate of capillary absorption increases as the dosage of NFC solution in the mortar increases. However, the rate of capillary absorption decreased for mix containing $1.28 \%$ and $1.60 \%$ NFC as compared to the mix containing $0.96 \%$ NFC. From the graph, it can be clearly observed that the rate of capillary absorption was maximum for the mix containing $0.96 \%$ NFC (i.e. $60 \%$ NFC solution).

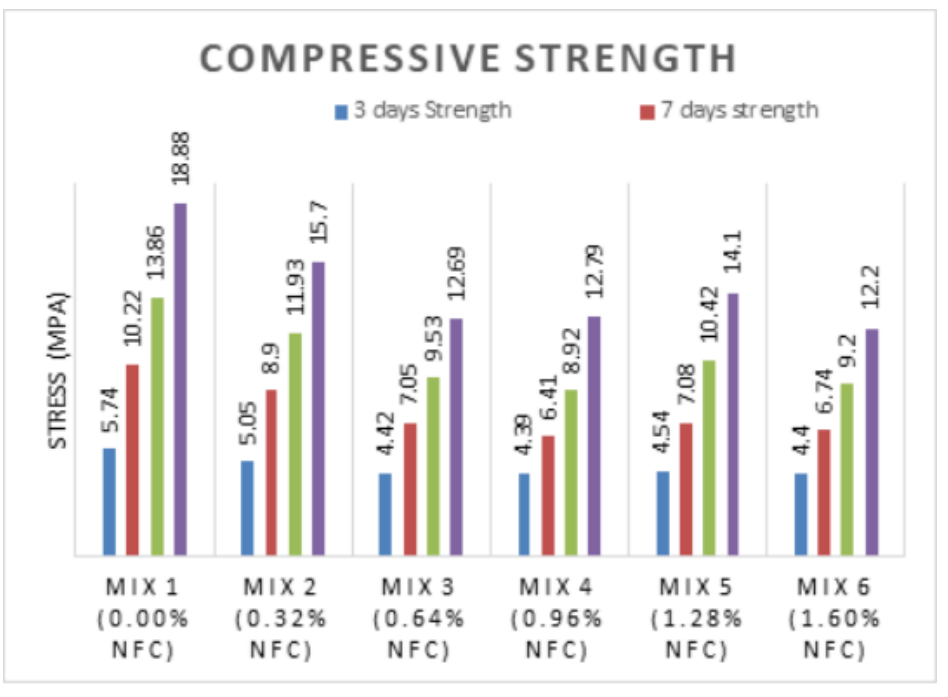

Figure 5 Variation in Compressive Strength for all mix

\subsection{Rendering Rebound Loss}

Variation in results for the rendering rebound loss for substrate as brick wall and AAC block wall is as shown in Figure 7. As the dosage of NFC solution in the mortar increases the rebound loss also increases up to the dosage of $0.96 \%$ NFC (i.e. $60 \%$ NFC solution). As the dosage of NFC was further increased the rebound losses tends to decrease. The wastage was observed more when the substrate was Brick wall than that when the substrate was AAC Block wall. The least amount of rebound loss was observed for Mix containing $1.60 \%$ NFC (i.e. 100\% NFC Solution). 
Priya Patel, Dr. A. S. Wayal and Dr. A. K. Bharimalla

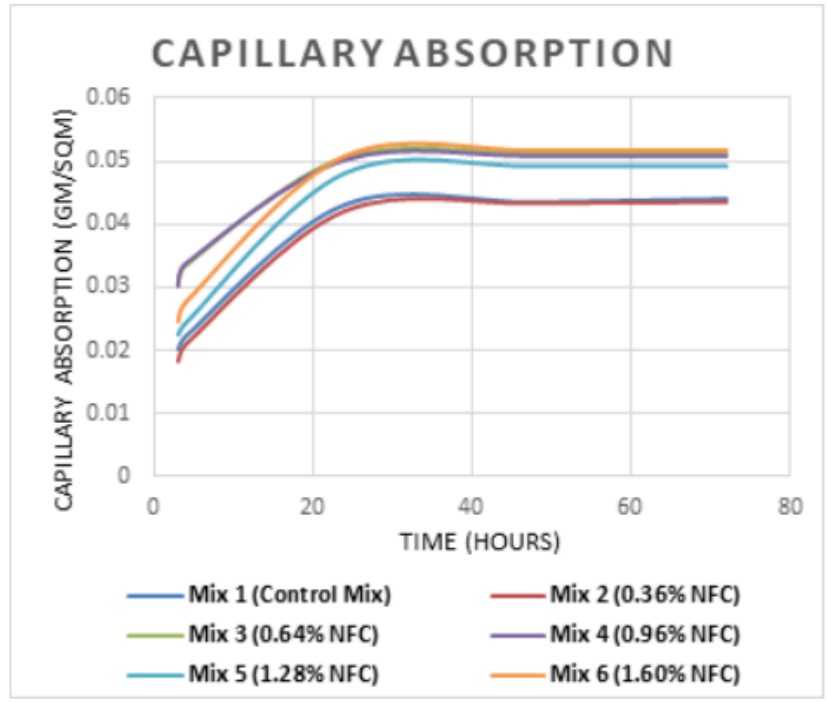

Figure 6 Variation in Capillary Absorption for all mix

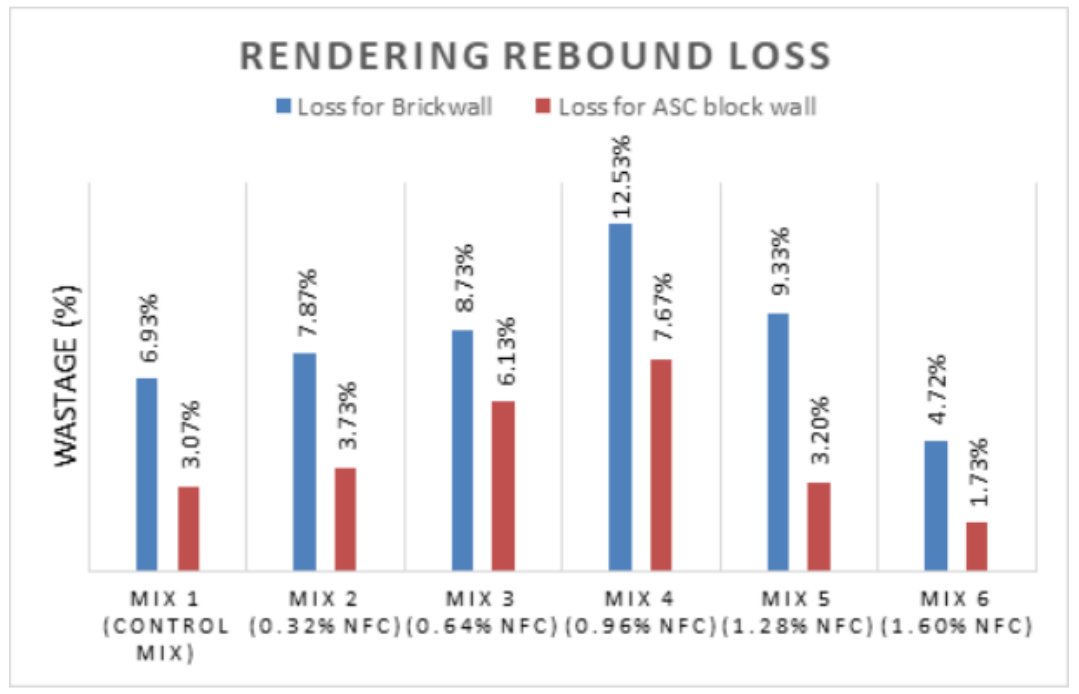

Figure 7 Variation of Rendering rebound loss for all mix

\subsection{Moisture in Mortar}

Figure 8 shows the variation in the results on moisture absorption at surface and $10 \mathrm{~mm}$ depth for 7 and 28 days for each trial mix. As the dosage of NFC Solution increased the moisture present $10 \mathrm{~mm}$ deep of the plaster increased and the highest percentage of moisture was observed for Mix containing $0.96 \%$ NFC (i.e. $60 \%$ NFC Solution) for moisture found at 7 days and $0.32 \%$ NFC (i.e. $20 \%$ NFC Solution) for moisture found at 28 days. For Moisture at the surface the initially increased as the dosage of NFC Solution increased however, after the moisture at the surface began to decrease when the dosage of NFC Solution became more than $0.96 \%$ NFC (i.e. $60 \%$ NFC Solution) by weight of cement. 


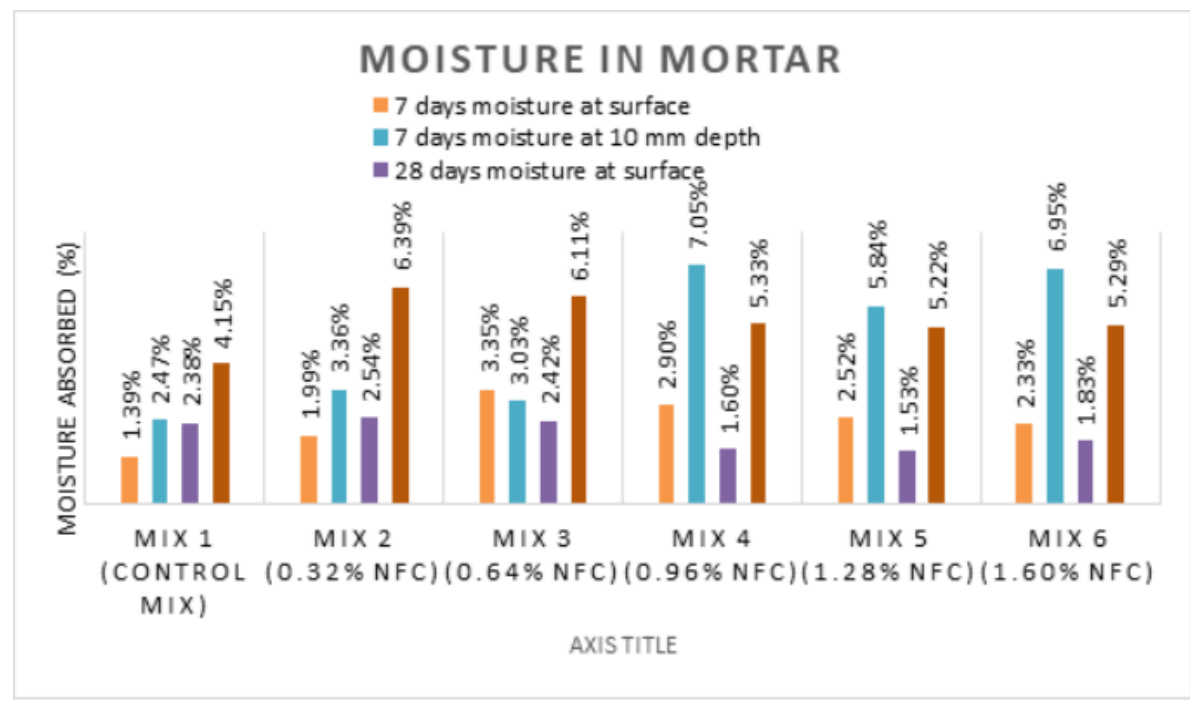

Figure 8 Variation in absorbed moisture for all mix

\subsection{Length of Cracks}

The length of the cracks observed on the plastered surface of AAC block wall decreased as the dosage of NFC solution in the mortar increased. The total length of the cracks measured for $0 \%, 0.32 \%, 0.64 \%, 0.96 \%, 1.28 \%$ and $1.60 \%$ of NFC in mortar were $74.6 \mathrm{~cm}, 62.5 \mathrm{~cm}$, $64.9 \mathrm{~cm}, 11.6 \mathrm{~cm}, 14.9 \mathrm{~cm}$ and $13.4 \mathrm{~cm}$ respectively.

\section{CONCLUSION}

Addition of Nano fibrillated Cellulose in fresh mortar results into decrease in workability. Workability can be enhanced by adjusting water/cement ratio. The density of fresh mortar decreases as the dosage of NFC increases, whereas the entrapped air inside the mortar increases as the dosage of NFC increases. Bleeding rate decreases as the NFC is added in the mortar.

The wastage of rendering mortar in AAC block wall was less as compared to brick wall. The surface moisture in the plaster is observed to increase with addition of NFC Solution, however, it decreases when the dosage of NFC increases more than $0.96 \%$ by weight of cement. The moisture at $10 \mathrm{~mm}$ depth in the plaster increases with increase in dosage of NFC and highest moisture observed was $7.05 \%$ for mix containing $0.96 \%$ NFC for 7 days moisture.

The rate of capillary absorption increases as the dosage of NFC solution increased. Maximum rate of capillary absorption was found for the mix containing $0.96 \%$ NFC. Also, the length of the crack on the plastered surface decreases as the dosage of NFC solution in the mortar increases.

\section{ACKNOWLEDGEMENT}

Lafarge Aggregates \& Concrete India Pvt. Ltd. provided valuable assistance in the sample preparation and testing phase. ICAR- Central Institute for Research on Cotton Technology (CIRCOT) provided the required Nanofibrillated Cellulose which is appreciated and acknowledged. 


\section{REFERENCES}

[1] J. Claramunt, M. Ardanuy, R. Arevalo, F. Pares and R. D. Toledo Filho (2011), "Mechanical performance of ductile cement mortar composites reinforced with Nanofibrillated Cellulose", 2nd International RILEM Conference on Strain hardening cementitious Composites, Rio de Janerio, Brazil, 131-138.

[2] M. Ardanuy, J. Claramunt, F. Pares, E. Aracri and T. Vidal (2012), "Nanofibrillated Cellulose as reinforcement for High Performance cement mortar composites", ECCM15 15th European Conference on Composite materials, Venice, Italy, 24-28.

[3] Monica Ardanuy, Josep Claramunt, Raquel Arevalo, Ferran Pares, Elisabetta Aracri and Terrsa Vidal (2012), "Nanofibrillated Cellulose (NFC) as a potential reinforcement for High Performance cement mortar composites", BioResources 7(3), 3883-3894.

[4] Monica Ardanuy, Josep Claramunt, Romildo. D. Toledo Filho (2012), "Evaluation of durability to wet/dry cycling of cement mortar composites reinforced with Nanofibrillated Cellulose", IFTR and Woodhead Publ, Warsaw, 33-41.

[5] Namrata Bhalerao, A. S. Wayal, P. G. Patil, A. K. Bharimalla (2015), "A review on effect of Nanocellulose on concrete", International Journal of Civil and Structural Engineering Research, Vol. 3, Issue 1, (251-254).

[6] Namrata R. Bhalerao, A.S. Wayal, P.G. Patil and A. K. Bharimalla (2016), "Application of Nano cellulose in concrete", Ecology, Environment and Conservation Paper Vol 22, Issue 2, 687-690.

[7] Obinna Onuaguluchi, Daman K. Panesar, Mohini Sain (2014), "Properties of nanofibre reinforced cement composites", Construction and Building Materials 63, 119-124.

[8] Roukaya Mejdoub, Halim Hammi, Joan Josep Sunol, Mohamed Khitouni, Adel M'nif and Sami Boufi (2016), "Nanofibrillated cellulose as nanoreinforcement in Portland cement: Thermal, mechanical and microstructural properties", Journal of Composite Materials, 1-13.

[9] Tiffany Abitbol1, Amit Rivkin, Yifeng Cao, Yuval Nevo, Eldho Abraham, Tal BenShalom, Shaul Lapidot and Oded Shoseyov (2016), "Nanocellulose, a tiny fiber with huge applications", Current Opinion in Biotechnology 2016, 39, 76-88. 